\title{
Quando a linguagem é imprescindível à sobrevivência: Ó, de Nuno Ramos
}

Mayara Ribeiro Guimarães ${ }^{1}$

Começo a ler Nuno Ramos e sem muita espera, sem muita cerimônia, sou lançada uma vez mais ao texto de Clarice Lispector. Penso logo de saída que isso pode ser uma armadilha. Sigo até o fim do primeiro movimento ou capítulo de $O$, intitulado "Manchas na pele, linguagem", escrito em prosa poética, e já não tenho dúvidas de que pensar em Lispector não é um disparate e tampouco armadilha de uma possível leitura contaminada. Começo a me indagar em seguida sobre o que exatamente me faz lembrar a prosa clariciana e passo a enumerar exemplos: o primeiro, já sugerido por Ana Kiffer em "Entre o Ó e o "Tato"": a relação entre corpo, linguagem e identidade; o segundo vou descobrir ter sido apontado por Ângela Dias no ensaio "Nuno Ramos e suas Torres de Babel: o criador e o tradutor" (Dias, 2012): a relação entre palavra e imagem, ou, posto pelo autor, entre matéria e linguagem, ainda que as pesquisadoras não apontem as relações entre a prosa de Ramos e a de Lispector. Mas foi sobretudo no problema do expressivo e inexpressivo que encontrei o solo por onde começar a trabalhar, conduzindo uma linha de reflexão que me faz pensar sobre a reatualização, na narrativa brasileira contemporânea, de questões de fundo problematizadas pelo projeto literário de Lispector e que já precipitavam, em sua escrita, futuros problemas abordados na estética contemporânea.

Em linha de reflexão semelhante está o artigo de Biagio D'Angelo “Ó, o lugar da negatividade". Nele o pesquisador conclui que a atemporalidade textual impressa pela obra de Ramos, conferindo-lhe posição central dentro da narrativa enquanto lugar de negatividade, é tema que, na contemporaneidade, vence a necessidade de ser superado ou apaziguado, uma vez que o romance não precisa mais se desconstruir para desconstruir a tradição da letra - o que mais uma vez me remete ao texto de Lispector.

Tendo a linguagem já se afirmado como "lugar da impossibilidade de dizer e revelar verdades" (D’Angelo, 2011, p. 311), importa pensar agora de que modo a literatura recupera seu posto de atividade autônoma, com leis próprias, seguindo a tradição aristotélica, já recusada como “linguagem-espetáculo, [...] linguagem cinematográfica banal, superficial, reduzida a um

\footnotetext{
${ }^{1}$ Doutora em letras e professora de literatura brasileira na Universidade Federal do Pará (UFPA), Belém, PA, Brasil. E-mail: mayribeiro@uol.com.br
} 
conjunto de gestualidades, propostas idiomáticas, de um cotidiano estéril e rotinário" (D'Angelo, 2011, p. 311). Isso possibilita a oscilação entre uma "afasia trágica" e a "busca desesperada de alguma coisa" (D’Angelo, 2011, p. 318), drama encenado pela narrativa brasileira contemporânea, anunciando um possível arrefecimento do vigor de uma prosa neo-realista no cenário atual.

Então, vejamos. O problema da relação corpo-linguagem coloca-se em conformidade com as observações feitas por Ana Kiffer em relação a uma crise de identidade - que apontará, como veremos, para um questionamento em torno da representação - aberta pela estranheza que a degenerescência do corpo provoca no sujeito. "Meu corpo se parece muito comigo, embora eu o estranhe às vezes" (Ramos, 2008, p. 11), registra a frase de abertura do romance. A crise é desencadeada quando o narrador, diante de um espelho, ${ }^{2}$ nota a ausência de pelos no queixo, sob a forma de "círculos calvos" (p. 12) de origem indefinida, como se fora "uma mordida" (p. 274), a romper a estrutura contínua do corpo. Logo os círculos se confundem com manchas - nódoa, cicatriz, acidente - a introduzir o signo da ausência no rosto do narrador e se abrir a uma devoração autofágica, que é do corpo e, sobretudo, da palavra.

A marca, ainda que seguindo a "rigorosa geometria" (Ramos, 2008, p. 12) aferidora de uma forma, a do círculo, tão assinaladamente simbólica - emblema ofídico e autofágico de metamorfose, fluxo incessante da vida que se abre para a morte (e vice-versa), do círculo que se torna espiral (Kiffer, 2010, p. 34-46) - indica, no entanto, uma abertura ao perigo que a emergente matéria amorfa provoca na identidade bem constituída desse corpo ordenado, que é também tradição da letra. Tanto a "doença" quanto a sua consequência máxima que é a morte "diversificam" a "homogeneidade" do corpo e quebram "a simetria do rosto" (Ramos, 2008, p. 273). O corpo instaura o outro do mesmo, essa parte estranha que conferirá novo sentido ao real e à linguagem, "clareira de envelhecimento infiltrada" (p. 273) no semelhante. Porque, como afirmará o narrador já no último capítulo do romance, intitulado "No espelho": "É a deformação minuciosa de pequenos detalhes da superfície do corpo [...], e a deformação de suas formas gerais [...] que lhe dão vida e interesse" (p. 274-275).

Na tentativa de reconhecimento do "nome definido" (Ramos, 2008, p. 12) da mancha que explique sua origem, o narrador in-corpora o problema nocen-

\footnotetext{
${ }^{2}$ A crise da representação, introduzida na crise da identidade desencadeada pelo elemento de estranhamento que a visão do rosto no espelho provoca, remete diretamente aos contos homônimos de Machado de Assis e Guimarães Rosa, intitulados "O espelho", mas também a A paixão segundo G.H., quando os olhos da barata esmagada por G.H. transfiguram-se em espelho a refletir os olhos, o rosto e o corpo da protagonista, inscrevendo Nuno Ramos como expoente contemporâneo de uma tradição do romance brasileiro que pensa a crise da representação na Modernidade, reatualizando o problema na contemporaneidade.
} 
tro da linguagem para pensar, inclusive, a sua origem e função. Porque o nome introduz a identidade. Para entender mais do fenômeno que acomete o corpo, o narrador deixa os pelos crescerem formando uma imagem - retrato - que capture na palavra o processo de transformação do corpo.

Como sugere o título do capítulo, as manchas e imagens de degenerescência se convertem em entalhes na tela da carne, tentativa de capturar o movimento de "mudança do corpo" e suas "sutis transformações" (Ramos, 2008, p. 15) na pele das palavras. Assim, o narrador inscreve a matéria no tempo, ao inscrever a ruína na linguagem. $O$ corpo se torna "amálgama de carne e tempo" (p. 15), e a linguagem "amálgama aflito de palavras" (p. 17) em busca de seu "halo de inexpressividade".

Na impossibilidade de comunicação da "inexpressividade" própria da natureza e de sua atividade, o homem substitui esse "fluxo" pelas "modulações da voz" (Ramos, 2008, p. 21), dando nome às coisas (Ramos, 2008, p. 20), "fabricando" um "falso duplo" para poupar a si mesmo da vertigem do abismo.

Entre todas as matérias internas e externas, entre todos os sólidos, os musgos e as mucosas, entre o que voa e o que afunda, entre o que plana e o que nasce do apodrecimento, selecionamos apenas a voz e o vento, organizados em acordes, para tomar por mundo, apenas a nós é dada a labuta das expressões faciais e dos gestos, apenas em nós a dor parece alhear-se numa expressão, facial ou linguística (Ramos, 2008, p. 21).

Reatualiza-se aqui o problema tão clariciano da nomeação, associado, em contraste, ao inexpressivo que, para Lispector, é o equivalente do inumano, neutro ou it. Em A paixão segundo G.H., a linguagem é apresentada como "esforço humano" que engrossa a humanidade com "conceitos grossos" (Lispector, 1979, p. 127), introduzindo a medida do acréscimo e da representação, da denominação ou dominação - "Eu tenho à medida que designo - e este é o esplendor de se ter uma linguagem. Mas eu tenho muito mais à medida que não consigo designar" (Lispector, 1979, p. 172). O nomear a si e ao outro garante a representação das formas no mundo interpretado pelas categorias do sujeito, mas desistir de dar forma ou nome ao informe é reconhecer a impotência e o fracasso do sujeito ao tentar domesticar o indomesticável, reafirmando o caráter insubjugável e, diria Ramos, a "potência-ó" da linguagem, sem prescindir da angústia de uma liberdade que garanta a existência dentro "daquilo que ainda não tem nome" (Lispector, 1978c, p. 70).

A linguagem leva a palavra às ultimas consequências matando a tradição da nomeação, da representatividade, da imagem e semelhança, em vigência desde Platão e Aristóteles, para que apenas o vigor do que está dado se repita, e não o seu simulacro, resgatando na linguagem o espaço de 
encenação do informe. Rompendo a simetria entre o nome e a coisa, Clarice (e também Nuno Ramos) revigora o antigo problema que envolve a representação da arte, vigente no princípio aristotélico da arte como mimeses da natureza, no sentido de recuperar um movimento da literatura próximo não da imitação do real estático e transparente, mas do fluxo de gestação inerente à physis. Junto a isso, reinstaura-se a tentativa de reabilitação de um elemento de autenticidade da palavra poética, daquilo que garante a autonomia do que é único. Voltaremos a esse ponto mais adiante.

O narrador de $O$, entretanto, concebe uma alegoria que possa explicar a origem da linguagem para tratar do problema da representação, numa espécie de mito de Theuth da linguagem. Nascida da necessidade de expressar a dor, a linguagem só poderia ter surgido em uma comunidade composta de doentes ("seres linguísticos") e sãos, também chamados de "heróis mudos", manifestando-se como moeda de troca dos doentes, espécie de "comunhão na doença" (Ramos, 2008, p. 22), expulsando do cenário os "heróis mudos" e tornando-se posteriormente um mecanismo do qual os homens não podiam mais se dissociar.

A linguagem inseriria, em seu berço, uma cisão entre "heróis mudos" e "seres linguísticos", numa espécie de cena originária sacrificial, que impede o retorno do recalcado, aquele "halo de inexpressividade" próprio da linguagem dos "heróis mudos", assumindo-se então como "ferramenta" (Ramos, 2008, p. 22), "substituindo-se ao real" (p. 23), "tão natural e verdadeira quanto uma rocha, um cajado ou uma cusparada" (p. 22). Lembremos que o risco duplo do desenho inscrito na parede de G.H. não é um ornamento, mas uma escrita, a da tradição e de seu reverso, de benditos e proscritos, do culto ao sublime e da hora do lixo, dos edifícios e das ruínas. Inventada para registrar uma marca fixa daquilo que desaparece, insufla-se na tentativa de preservar-se da morte e do esquecimento, como no mito de Theuth, num ensaio de duplicação da linguagem dos "heróis mudos". Jamais a palavra poderia recuperar a sua condição de matéria física, agora já um "signo sem matéria" (p. 30).

O mais próximo que o homem chegaria de um fora da linguagem, espécie de reencenação da cena pré-sacrificial, seria pela associação a outras linguagens que lhe assegurassem carga sinestésica, para além dos signos, de modo a preservar o "alfabeto físico" (Ramos, 2008, p. 29) dos "heróis mudos" e seu halo de inexpressividade, capturando a linguagem da coisa viva, composta de matéria perecível. (A cena de origem só poderia ser reencenada quando o homem entra em contato com a arte.) Mas, antes de desaparecerem completamente, os "heróis mudos" teriam lançado uma maldição, transformada em enigma, a perseguir "todas as línguas vivas 
ou mortas" (p. 26), que encontraria abrigo também no corpo do homem. Nesse ponto, testemunha-se a compreensão de que, neste ensaio poético, é o corpo que introduz a identidade, e não a nomeação, rasurando também o amparo da arte representativa: a forma.

Vivendo a agonia da impossibilidade de expressar o inexpressivo, a linguagem em $O$, ao inscrever o fluxo na matéria linguística por meio da escrita da degenerescência no corpo, faz despertar o "corpo profundo" (Ramos, 2008 , p. 26), esse estranho outro do mesmo. Nesta atualização, único momento em que se rompe o simulacro, porque "a dor não se duplica" (p. 26), a linguagem imprescindível à sobrevivência passa a ser aquela que "servisse apenas para iludir a rebelião e o mau funcionamento do corpo" (p. 27) e pudesse pronunciar "o nome de nossa doença" (p. 27). Em outras palavras, a linguagem realizável e legítima é aquela que não poupa "a parte pânica, corpórea e dolorida", precipitada pela morte, pela velhice e pela perda, que se funda como linguagem dos "alfabetos físicos" (p. 29), onde a leitura seria uma espécie de sexto sentido; onde o texto seria sinestesicamente cor, música, mímica, e ainda desenho, sangue, nuvem, animal, voo, tronco, cuspe.

Mas é então, sob a sentença de um envelhecimento inevitável, que alguma coisa em mim parece querer, e poder, sobrevoar meu corpo, livrar-se dele - um misto de olhar para longe e de respiração, um amalgama aflito de palavras, a melodia como porta ou túnel, o instante que cava minha pegada numa paisagem imensa. Mas esta alegria progressiva precisa de alimento constante e o próprio corpo, em sua casca, parece não resistir bem a ela, tornando-se inquieto, ofegante e, aos poucos, cansado e deprimido. Como um balão cujo gás vai escapando, a energia insana de nossa alegria física procura abrigo - nas imagens, nos braços de outra pessoa e, no limite, pois é a isto que sempre recorre, na linguagem (Ramos, 2008, p. 17).

A palavra insere-se como limite entre sujeito e mundo; evento que separa o um e o outro, projeta o sujeito "para fora do corpo" (Ramos, 2008, p. 18), erguendo imagens que conferem fisicalidade à palavra. E aqui já não posso escusar-me de me remeter a Água viva, de Lispector. A prosa poética de Ó volta a problematizar temas centrais vinculados ao romance da autora, em especial aquele que privilegia a potência de porosidade e provisoriedade da linguagem em manifesto esforço de abandono da representação, nomeação, ou expressividade. Gesto generoso que se coloca no núcleo da cena de teatralização do imaginário, capturado pela linguagem em quadros que recortam o instante-já do vivo, na tentativa de "unir pedaços de frases a pedaços de coisas vivas" (Ramos, 2008, p. 19), pendor ao fragmento.

Como uma via intermediária, procuro entrar e permanecer no reino da pergunta - ou de uma explicação que não explica nunca. [...] 
Posso, até mesmo, anotar em meu caderno características do que toco, como: "pinta-se de verde antes de reproduzir", "mostra extrema ansiedade antes do ocaso", ou "destila o breu dos carvalhos ao redor" (Ramos, 2008, p. 19).

Encenando o real tal qual um quadro, a palavra ganha materialidade, "um sentido quase que só corpóreo" (Lispector, 1978, p. 11), de modo que passe a compartilhar da mesma materialidade que a tinta. Quem explica o processo é Lispector:

É tão curioso ter substituído as tintas por essa coisa estranha que é a palavra. Palavras - movo-me com cuidado entre elas que podem se tornar ameaçadoras; posso ter a liberdade de escrever o seguinte: "peregrinos, mercadores e pastores guiavam suas caravanas rumo ao Tibet e os caminhos eram difíceis e primitivos". Com esta frase fiz uma cena nascer, como num flash fotográfico (Lispector, 1978, p. 23).

Quero com isso chamar atenção para o fato de que, ao buscar amparo na imagem, antes de buscar a associação de outras linguagens que lhe garantam representatividade, privilegia-se o tema do deslocamento, vigor da poesia. O caráter corpóreo da textualidade é estratégia da linguagem para tornar o texto espaço de reflexão e produção literária, para pensar a arte e sua práxis fora do império da tecnologia, inscrevendo o sujeito na história. A estranheza que emerge desse movimento aponta para a contemplação da linguagem como ruína, desarticulação necessária que pensa o problema da representação na cultura de massa, deslocamento que se torna espaço onde a palavra cumpre a sua encenação. A desarticulação proposta pela escrita de Nuno Ramos abala os alicerces do romance contemporâneo de tom neorrealista, recusando os procedimentos constitutivos desse tipo de prosa, procurando recuperar uma tradição literária em que a literatura vige como produtora de sentidos e não como reprodutora de sensações.

Chamemos o agente desse deslocamento de informe, no sentido dado a esse termo por Georges Bataille, associando-o à noção de heterogêneo e operando-se por uma tarefa de desclassificação daquilo que garante ordenação a uma forma. A forma, por sua vez, é definida por Bataille (em textos como "O valor de uso de S.A.D. Sade" e "A noção de despesa") pela tendência do homem civilizado em homogeneizar aquilo que se apresenta por meio da diferença, ou também do heterogêneo. Consideremos que o informe incumbe-se da tarefa de estilhaçar a forma, reivindicando a abertura a um elemento perturbador interno a ela própria, espécie de deformidade implícita, dessemelhança que impedirá a homogeneização das coisas, retirando o foco do sentido das palavras e voltando-o para a tarefa de desestabilizar e desclassificar. A linguagem, aberta agora para o fluxo da mutação 
própria do que é vivo e engendra o deslocamento, passa a ser o lugar onde se desempenha uma performance, que dramatiza a potência de dilaceramento e intensifica a tarefa do que é, per se, inacabado e precário.

Por que então elaborar uma alegoria que trate do nascimento da linguagem? Antes de tudo para apontar, ainda e mais uma vez, hoje, que é a linguagem o centro privilegiado de discussão da obra, de qualquer obra que se queira e se faça literária, sobretudo no que diz respeito à questão da representação. Captando os rastros do terremoto na e da linguagem, da crise deste verso-prosa do novo século, pode-se mergulhar no fluxo do magma e tratá-la como linguagem de "pedaços e destroços" (Ramos, 2008, p. 31), murmúrio do "nome-amor" (p. 177) das coisas. Pensar a linguagem nesse fluxo permite tocar no problema entre cultura e natureza, central para a contemporaneidade.

Por esse percurso caminha brevemente o ensaio de Ângela Dias mencionado anteriormente. Nele a autora identifica a prosa de Nuno Ramos como resistência à operação que a tecnologia inflige na sociedade, enquanto ferramenta de disseminação da cultura de massa, como força capaz de "abolir toda uma ambivalência em favor de uma função única" (Dias, 2011, p. 19). A cultura da tecnologia introduz o problema da representação em termos da oposição entre uma materialidade própria da natureza ainda não tornada produto da técnica, em termos benjaminianos, e uma imaterialidade vigente na tecnologia.

Seguindo as sugestões dadas por Dias, o problema se inscreve no romance de Nuno Ramos no sentido de que captar as ruínas da linguagem nas marcas de deformação do corpo permite o "distanciar-se dos próprios automatismos" (Ramos, 2008, 127) que são do corpo, mas também da cultura. Com isso, a literatura, tanto quanto o corpo, se insere na cultura do contemporâneo como espaço de desautomatização da palavra, afastando-a da "matéria inerte" para que possa se parecer mais com "corpos elásticos feitos para o banho e para a tarde vermelha" (p. 129). A deformação do corpo, que provoca marcas na matéria, seja por meio do envelhecimento e da doença, seja na prática de mutilação, comum em muitas culturas, é entendida como a antecipação da morte pela presentificação da materialidade da carne, concedendo "peso e gravidade" à "carne contínua do corpo jovem" (p. 275), trazendo para próximo de si a ruína do "estar vivo".

A "nódoa" no queixo, que se tornou, no último capítulo, "uma mordida" (Ramos, 2008, p. 274), passa a representar esse dado de debilidade, inserindo a dimensão autofágica do "corpo acidentado" (Ramos, 2008, p. 275) aberto a uma "ambiguidade" que interrompe o gesto de continuidade e homogeneidade, ao gosto de Bataille. Essa mordida, em forma de Ó, 
aponta para a letra-orifício, título do romance, e para a "potência-nuvem" de "destino voz" (p. 104) da linguagem guardada em seu interior. A letra, também boca onde habita o canto dos destroços, comporta a ambiguidade de uma significação excrementícia e deglutiva: "dentre todos os orifícios do corpo" (p. 157) o único em que "se confundem coisas tão díspares, boca que pede perdão e conta a mentira, a notícia, que lambe a vagina e prova a verdura, boca da fala, dos hematomas, da cacofonia" (p. 157). A boca que elabora a palavra, cuja "sina de sempre fazer sentido" "sequestra" o vivo do homem, desprende-se no seu outro-gêmeo de si mesma e permite o cumprimento da tarefa do narrador: "dar a voz à matéria", que é igualmente "dar à matéria a sua voz" (Ramos, 2008, p. 155).

A fissura provocada pelo naufrágio da linguagem manifesta-se por meio de imagens que circulam entre o tangível e o intangível, o figurativo e o abstrato, o visível e o invisível, imagens que não se enraízam nem em um território, nem em outro, porque intencionam atualizar o lugar em que a linguagem se torna agenciamento da enunciação, como propõem Deleuze e Guattari. Exprimindo esses agenciamentos, a literatura reivindica a força diabólica e revolucionária de um coletivo desterritorializado, um coletivo menor a exercitar seus conteúdos próprios, no seio de uma literatura maior. Nessa margem, como afirmam os filósofos acerca da obra de Kafka, a literatura ergue um espaço mais apto ao trabalho da matéria (Deleuze e Guattari, 2002, p. 40-42). Ao buscar esse movimento, a obra de Nuno Ramos abandona a noção de realismo e representação, recuperada por correntes da atual narrativa brasileira, em nome da permanência da literatura como lugar de teatralização dessa mesma tradição. Na representação da realidade pela literatura interessa o rasgo, o duplo, a dobra, decorrentes da relação entre real e ficcional, e a dimensão violenta do sucumbir, que sobrevive na realidade como resíduo e ruína, retornando ao cotidiano em seu aspecto banal e diário. Como a visão, no espelho do banheiro de um restaurante qualquer, de uma mancha estranha no queixo de um homem.

A ferida aberta no corpo da linguagem provoca um movimento de dobra da subjetividade, que passa a encenar o drama de sua condição fraturada, denunciando o trabalho do heterogêneo realizado sobre as forças de homogeneização e domesticação impostas pela e sobre a linguagem ao longo da tradição literária ocidental. Manter vivo o exercício do heterogêneo possibilita a sustentação de uma ambivalência própria do registro do duplo, a partir do deslocamento das formas e da operação de suas instabilidades. Nesse sentido, a encenação do heterogêneo se organiza no ponto em que se instala o déficit do sistema, para que a linguagem inicie o seu trabalho de desarticulação em nome de algo novo. 
A irrupção do heterogêneo possibilita a encenação do duplo em diferentes formas. A repetição ou reconvocação da tradição cultural e literária ocorre de forma que o seu desgaste por meio da encenação estética do Realismo prove que o resíduo pode atuar como dissonância para que haja a crítica da representação e a instauração da morte. Subverte-se o traço realista e mimético da relação entre ficção e realidade permitindo-se a captura do imaginário em contato com o real pela palavra, de forma que as rasuras e ausências adentrem o palco da narrativa, e esta se torne o lugar da dobra e do devir da escrita. Desabitar a língua para torná-la sua. Desapropriar-se do próprio para tornar-se estrangeiro em si. Desoprimir a língua para acercar-se das zonas de subdesenvolvimento, por onde "a língua se escapa" e "um animal se enxerta" (Ramos, 2008, p. 56). Ao buscar o intangível no tangível do real, abandona-se a rigidez da identidade em nome do fluxo. Longe de se associar àquilo que designa, a linguagem de Ó se abeira de sua origem como um Fiat lux, uma fulguração, para fora da comunicação e para dentro do que se ausenta da necessidade de comunicar, porque é. Claricianamente.

\section{Referências}

BATAILLE, Georges (1967). A parte maldita. Rio de Janeiro: Imago.

D'ANGELO, Biagio (2011). Ó, o lugar da negatividade. In: Novas leituras da fiç̧ão brasileira no século XXI. São Paulo: Mackenzie.

DELEUZE, Gilles; GUATTARI, Félix (2003). Kafka. Para uma literatura menor. 1. ed. Lisboa: Assírio e Alvim.

DIAS, Ângela (2011). Nuno Ramos e suas torres de babel: o criador como tradutor. In: Tradução literária: a vertigem do próximo. 1. ed. Rio de Janeiro: Beco do Azougue. KIFFER, Ana (2010). Entre o Ó e o “Tato”. Alea: Estudos Neolatinos, v. 12, n. 1, p. 34-46. LISPECTOR, Clarice (1978). Água viva. 3. ed. Rio de Janeiro: Nova Fronteira. (1979). A paixão segundo G.H. 6. ed. Rio de Janeiro: Nova Fronteira.

RAMOS, Nuno. Ó. São Paulo: Iluminuras.

Recebido em dezembro de 2011. Aprovado com alterações em março de 2012.

Reapresentado em maio de 2013. Aprovado em maio de 2013. 


\section{resumo/abstract}

\section{Quando a linguagem é imprescindível à sobrevivência: Ó, de Nuno Ramos}

\section{Mayara Ribeiro Guimarães}

Desenvolvendo tema tão privilegiado pela literatura quanto o da orgânica relação entre corpo e linguagem, o romance $O$, de Nuno Ramos, tangencia os limites entre escrita do corpo e escrita da morte a partir de uma crise da linguagem desencadeada pela degenerescência do corpo. A crise provoca um estranhamento entre subjetividade e corpo, identidade e linguagem que, em consequência, instaura uma escrita da deriva. A dimensão da deriva passa a ser encenada por meio da articulação entre a tradição literária e a fratura causada na linguagem pelo contato com o residual. Nesse movimento, a obra de Nuno Ramos abandona a noção tradicional de realismo e representação em nome da teatralização dessa mesma tradição e da própria escrita. Seguindo estes caminhos de reflexão, buscarei retratar os aspectos abordados pela obra de Nuno Ramos dentro de uma perspectiva da literatura brasileira contemporânea que ressignifica questões de fundo problematizadas pela tradição literária brasileira e por precursores da estética contemporânea, como Clarice Lispector.

Palavras-chave: Nuno Ramos, Clarice Lispector, narrativa brasileira contemporânea, crise da representação, corpo e linguagem.

\section{When language is essential to survival: $O$, by Nuno Ramos}

\section{Mayara Ribeiro Guimarães}

Developing the well known literary theme of the organic relationship between body and language, $O$, novel by Nuno Ramos published in 2008 , touches the boundaries involving body, death and writing, from the perspective of the language crisis opened up by the experience of aging and body decay. The crisis leads to a non-recognition between the subject and the body, identity and language, which, as a result, engenders a language comitted to the experience of drifting. This experience is then staged by the dialogue of literary tradition and the rupture provoked in language by the contact with the residual. Following this track, Nuno Ramos' novel breaks lose from the traditional concept of realism and representation in literature on behalf of the staging of both literary tradition and the act of writing. This essay tries to portrait the problems engaged in this novel involving the debate of 
how contemporary brazillian literature brings back important issues questioned by brazillian literary tradition represented by pioneers of contemporary literature, such as Clarice Lispector.

Keywords: Nuno Ramos, Clarice Lispector, Brazilian contemporary narrative, representation crisis, body and language. 